\title{
CONCEPT OF RURAL SPATIAL PLANNING IN LINE WITH SOCIAL EXPECTATIONS
}

\author{
Joanna A. Pawlowicz, Elzbieta Szafranko \\ University of Warmia and Mazury in Olsztyn, Poland \\ jopaw@uwm.edu.pl,elasz@uwm.edu.pl
}

\begin{abstract}
Religious faith and worship are an indispensable part of human life. They are particularly important in small communities, in which family bonds are strengthened by common celebration of church holidays and ceremonies. Situated in the Warmińsko-Mazurskie province of Poland, the village of Lipy boasts a Marian sanctuary, popular among many Polish Catholics. However, the space around the church is not sufficiently developed. Each year, the village is visited by thousands of pilgrims, who need a properly designed infrastructure. This paper discuses the methodology and effects of actions undertaken to address the issue of planning the village's spaces in such a way as to allow the sanctuary and its surroundings to cater to the needs of the society. Preparing the project required performing an analysis of the functions, which particular elements of this public space could perform. To this end, a field research was conducted, along with an analysis of the literature on the issue and a survey among the local people. This allowed the researchers to become familiar with the social expectations related to the development of this part of the village. Finally, a project was drawn up to redesign the public space around the church. This paper constitutes only a part of a larger study, yet it proves that correct planning of any public space may not take place without the society's participation.
\end{abstract}

Keywords: rural areas planning, public space, religious worship, social participation

\section{Introduction}

The man shapes the space around him. There are fewer and fewer places where the landscape is shaped by the nature alone. Among them are rural areas, in which naturally shaped and undeveloped spaces can still be found. However, the needs of people inhabiting the rural areas are similar to those of people living in cities. They too want to live in high-standard houses, stroll down comfortable sidewalks, have access to sport and recreation facilities or cultural and religious events. In rural areas there are many centres of religious worship popular among the local people. On the other hand, the idea of living or staying in the country is becoming increasingly popular among city dwellers. Irrespective of where one comes from, almost everyone wants to satisfy their needs and have influence on the way their surroundings are shaped. In short, most people want the spaces around them to be designed in an aesthetic and functional way $[1 ; 2]$.

Changes in technology and culture trigger new needs and ideas related to the use of land, which has a significant influence on the quality and comfort of life. The well-being of the country dwellers is the centre of focus of both the local and church authorities, who act upon their initiatives. In many villages there are buildings and areas administrated by the local government or the parish. They can integrate and develop the local culture, as well as serve as places in which to enjoy one's hobbies, do sports or rest [3-5].

\section{Methodology and the research object}

Currently, many projects are co-financed by the EU funds. However, one must first become familiar with the needs and expectations of the local community and its financial situation. This is very important from the point of view of the intensity, direction and quality of activities to be undertaken, especially in the private space. Public spaces should be available to everyone [6]. In addition, they should be developed in such a way as to make their users feel that their comfort of life has increased. Therefore, one must become familiar with their needs. The most popular way in which to determine the way in which a village is to develop is by conducting a survey [7]. To this end, in 2015 a survey was conducted in selected villages of north-eastern Poland. In addition, a field research was performed, including an analysis of the literature available on the subject. The field research consisted in analysing the spatial development of selected areas. To this end, historical and social aspects of spatial development of selected villages were analysed. Particular functions in a given area were identified, along with the possibilities of implementing them. Finally, corrective actions were recommended, aiming at meeting the expectations of people living in the selected area. 
This paper focuses on the results of a research conducted in the village of Lipy situated in the Warmińsko-Mazurskie province of Poland. The village was named after a lime tree that grew there in the 13th century, under which the Prussian community inhabiting the area prayed to the goddess Majuma. According to a local legend, once, when the local people were saying their pagan prayers, the Holly Mother appeared in the tree [8]. To commemorate this miraculous event, a wooden church was built. It was later destroyed and in 1626 it was replaced by a brick building. In 1861, the church burnt down. In 1870, a new church was built in the neo-Gothic style, which survived to our times (Fig. 1). Gradually, more and more houses were built around the church to finally form a village. Currently, the church is known as the Holly Mother of Lipy Sanctuary, and is popular among pilgrims from all over the country [9]. The village is currently inhabited by people who have nothing to do with farming. Most of them work in industrial plants in the nearby town of Lubawa. Nevertheless, the village has retained its idyllic climate.

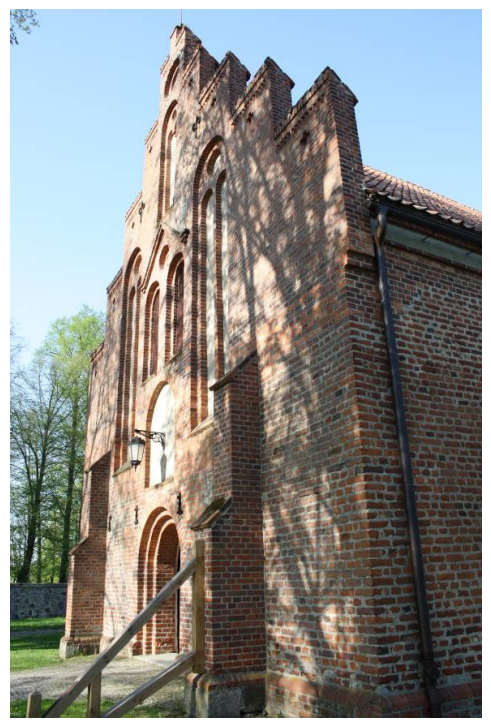

Fig. 1. Holly Mother of Lipsk Sanctuary - entrance (source: autor)

Religion and the possibility to demonstrate one's faith is an important part of living in small communities. The division between the sacred and the profane is very clearly visible in a village.

The profane means anything secular, anything that serves the community in its everyday life to meet its basic needs. The profane includes, e.g., houses and their surroundings. The sacred refers to faith and the church. It is related to religious worship. It is frequently symbolized by architecture and shapes the local culture and history. It covers places in which to satisfy one's spiritual needs. In the case of the village of Lipy, the sacred is the sanctuary and its surroundings. According to the survey results, it is the sanctuary that is the main concern for the local people.

\section{Scope of research}

The sanctuary is a popular religious site. This is why the documents and records kept by the parish were examined in the course of the research. According to them, the indulgence ceremony held on the first and second of July each year is attended by as many as seven thousand pilgrims from all over the country, arriving on foot, by car or coach. However, this is not the only time when pilgrims visit the sanctuary. The church is also a popular wedding place. However, it is mainly used by residents of the village itself and the residents of the nearby town of Lubawa.

According to the survey, the area around the church should be developed in such a way as to provide a space in which to hold holy masses, to contemplate and to accommodate the pilgrims. In order to get to know the needs of the users of this space, a survey was conducted among the residents of the nearby town of Lubawa, as they represent a target group of users of this place. The survey was conducted on the streets of Lubawa among 136 randomly selected people. One of the questions they were asked was: "What do you think the Marian Sanctuary of Lipy lacks the most?" The respondents answered as follows:

- 61 people said the parking lots need improvement; 
- 45 people expected a place to seat in front of the field altar;

- 11 people said a pilgrims' home should be built there;

- 9 people said the sanctuary needs a place in which to rest;

- 10 people said they were not familiar with the place at all.

On average, every sixth person mentioned an additional attraction and a better catering commercial facility. It would encourage them to spend more time there with their families and friends. Most respondents, however, pointed to parking lots and reorganization of traffic thereon as the priority.

The research included a survey of the existing infrastructure. To this effect, the technical condition of the church and the surrounding buildings was analysed, along with the technical infrastructure, roads and greenery. The analysis involved taking pictures of these facilities. This allowed for isolating functionally homogeneous research fields to focus on developing solutions appropriate for each particular function. The following research fields were isolated (Fig. 2):

- research field no. 1 - the church and the surrounding area;

- research field no. 2 - the field altar and the surrounding area;

- research field no. 3 - the toilets and the garden;

- research field no. 4 - parking lots;

- research field no. 5 - the way of the cross;

- research field no. 6 - greenery;

- research field no. 7 - walkways and roads.

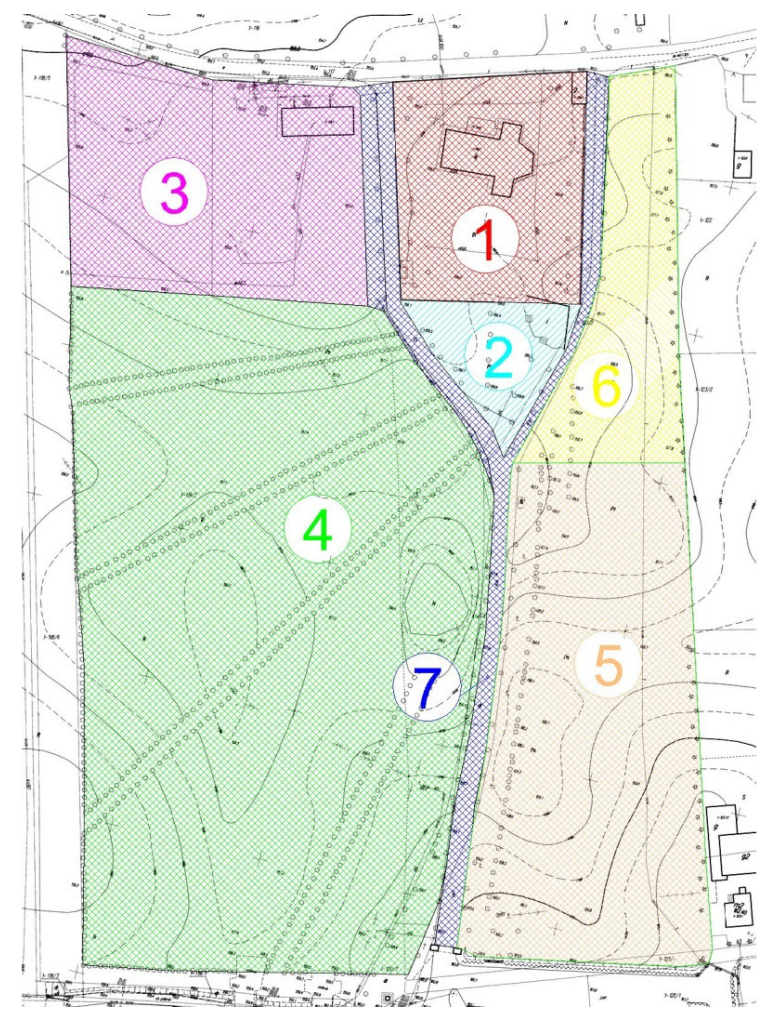

Fig. 2. Division into research fields (source: Own elaboration based on the numerical map of the town of Lubawa)

During the survey, most of the respondents pointed to parking lots as the area needing the biggest improvements. Therefore, this study focuses on research field no. 4 .

\section{Characteristics of research field no. 4: parking lots}

This is the biggest research field of $27000 \mathrm{~m}^{2}$. Its eastern part is occupied by a reservoir of an area of $300 \mathrm{~m}^{2}$. The remaining area is an unpaved parking lot. It can be accessed from the south by two roads paved with concrete blocks. 
The grass surface suffers serious damages during intensive use, especially when it rains. A big problem is coaches, for which there are no separate parking spaces and which park on the unpaved surface, forming ruts due to their weight. Another problem is the lack of clearly marked parking spaces, which causes chaos and frequently triggers negative emotions.

The parking lots are separated from one another by lime tree alleys, which appears to be a very good spatial arrangement. The lime trees growing on the southern and western side of the parking area form a natural fence. The alleys are arranged radially relative to the field altar. Thanks to such arrangement the altar is clearly visible from each alley. During the research, a number of ill trees were identified and recommended for removal due to safety reasons. They could be replaced with new ones.

\section{Corrective actions concept}

Most of the respondents pointed to the need to improve the parking lots near the sanctuary. They stressed the importance of improving the traffic arrangements and paving the parking surfaces. According to the information provided by the parish, as many as 300 cars are parked there during holidays. For safety reasons, it was recommended that one-way traffic be introduced on the $3.5 \mathrm{~m}$ wide alleys. Additionally, in order to facilitate parking, angled parking spaces were designed. This means, that cars will be parked at the angle of 45 degrees relative to the alleys. This will increase safety and make parking and manoeuvring easier. A total of 392 parking places were designed for passenger cars, including 27 parking places for disabled people arranged near the field altar and the church. 6 parking places were designed for coaches.

Given the nature of the place, the proposed solutions require removing only a small portion of the green areas. Greenery makes one calm and is conducive to contemplation, which is welcome in such places. Therefore, it was recommended that the parking lots not be covered with concrete blocks or bituminous coating, which would require building a drainage system.

In order to keep as much space as possible biologically active, the parking places will be covered with a plastic grid filled with grass. This way the surface will be reinforced and the grass will still be able to grow on it. Each parking lot will be clearly marked by means of plastic bolts with heads of 01 . $\mathrm{m}$ in diameter. They will be drawn into the ground to mark the boundaries of each parking place.

As traffic is to be one-way only, additional passages were designed between the alleys to facilitate manoeuvring. They will also be made of a plastic grid. However, they will additionally be covered with aggregate to stress their intended use.

These improvements will require cutting four trees, which currently impede the car and pedestrian traffic between the alleys. The alleys are also used by pedestrians, so cutting the trees will make it easier for them to walk between cars.

Most of the respondents pointed to the need to improve the parking lots near the sanctuary. They stressed the importance of improving the traffic arrangements and paving the parking surfaces. According to the information provided by the parish, as many as 300 cars are parked there during holidays. For safety reasons, it was recommended that one-way traffic be introduced on the $3.5 \mathrm{~m}$ wide alleys. Additionally, in order to facilitate parking, angled parking spaces were designed. This means, that cars will be parked at the angle of 45 degrees relative to the alleys. This will increase safety and make parking and manoeuvring easier. A total of 392 parking places were designed for passenger cars, including 27 parking places for disabled people arranged near the field altar and the church. 6 parking places were designed for coaches.

Given the nature of the place, the proposed solutions require removing only a small portion of the green areas. Greenery makes one calm and is conducive to contemplation, which is welcome in such places. Therefore, it was recommended that the parking lots not be covered with concrete blocks or bituminous coating, which would require building a drainage system.

In order to keep as much space as possible biologically active, the parking places will be covered with a plastic grid filled with grass. This way the surface will be reinforced and the grass will still be able to grow on it. Each parking lot will be clearly marked by means of plastic bolts with heads of 01 . $\mathrm{m}$ in diameter. They will be drawn into the ground to mark the boundaries of each parking place. 
As traffic is to be one-way only, additional passages were designed between the alleys to facilitate manoeuvring. They will also be made of a plastic grid. However, they will additionally be covered with aggregate to stress their intended use.

These improvements will require cutting four trees, which currently impede the car and pedestrian traffic between the alleys. The alleys are also used by pedestrians, so cutting the trees will make it easier for them to walk between cars.

\section{Conclusions}

Rural areas are undergoing a transformation. They are becoming increasingly popular with people who have nothing to do with farming. They treat them as places in which to relax after a hard day's work spent in the city. Fresh air, peace and nature attract many. The spatial arrangement of villages changes to cater to the needs of the newcomers. Their opinion, as well as the opinion of visitors, must be taken into consideration. This is of particular importance in places of religious worship, where the local space is available to everyone and therefore should be friendly. Preparing the concept of redesigning the space around the sanctuary required a significant research effort, including studying numerous documents, records and literature, as well as the applicable law. The area was thoroughly surveyed. All this has helped design changes to the spatial structure and functionality of the area. The most important thing, however, was the survey conducted among its users. It helped to identify people's expectations with respect to the sanctuary. The surveys proved to be a very valuable research tool. Their results helped determine the needs and expectations of the users of this area. People's participation at the stage of preparing concepts of any solutions related to changing public spaces is very important and necessary not only in the countryside. It gives investors a certainty that their ideas will be accepted by the local community.

This study is only a fragment of a larger study involving a vast research and analyses, but it shows how important it is to properly prepare and introduce changes to the use of land. What is also of great importance is continuous supervision over an object and introducing changes in the way it is used to adapt it to the needs of its users.

\section{References}

1. Hegarty C., Przezborska, L. Rural and agritourism as a tool for reorganising rural areas in old and new member states - a comparison study of Ireland and Poland. International Journal of Tourism Research, 7(2), 2005, pp. 63-77.

2. Witkowska-Dąbrowska M., Bączkowski T. Indicators of Warmińsko-Mazurskie voivodship sustainable development in the economic aspect. Olsztyn Economic Journal, 2(5), 2010, pp. 258-268.

3. Berdysz M., Kuliński M. Planowanie i zagospodarowanie przestrzenne w praktyce. Wydawnictwa Verlag Dashofer, 2005.

4. Pawłowicz J. A., Influence of green areas on urban landscape. Technical Sciences (13), 2010, pp. 113-119.

5. Szafranko E., Evaluation of a possible development of the transportation network in Poland supported by the EU funds. Olsztyn Economic Journal, 2(5), 2010, pp. 357-379.

6. Zabłocki G. Social problems of rural areas in Poland. Monatsberichte über die Österreichische Landwirtschaft, 47(9), 2000, pp. 634-639.

7. Liu A. Q., Besser T. Social capital and participation in community improvement activities by elderly residents in small towns and rural communities. Rural sociology, 68(3), 2003, 343-365.

8. Sulimierski F., Walewski W. Słownik geograficzny Królestwa Polskiego i innych krajów słowiańskich, 1884, T. V.

9. Śliwiński J., Lubawa. Z dziejów miasta i okolic, Wydawnictwo Pojezierze, 1982,Olsztyn 